\title{
PEMANFAATAN SAINS DAN TEKNOLOGI SEBAGAI UPAYA MENINGKATKAN SUMBER DAYA UMAT HINDU
}

\author{
Oleh : I Wayan Dana
}

\begin{abstract}
Abstrak
Perkembangan sains dan teknologi dewasa ini telah menuju pada suatu pendekatan akan peranan sains dalam menjelaskan fenomena spiritual. Toudam Damodara Singh Ph.D, seorang saintis dan juga rohaniawan menyatakan dalam bukunya berjudul The Scientific Basic of Krishna Consciousneess, menyebutkan bahwa ,"Hendaknya sains dijadikan sarana untuk menjelaskan keberadaan Tuhan (Krisna) dan bukannya menjadi semakin jauh dengan prinsip kesadaran mutlak". (T.D. Singh. 2006). Kenyataannya, dalam beberapa bidang pengetahuan, ilmu pengetahuan modern telah menemukan fakta-fakta yang sebelumnya sudah ada dalam literatur Veda ribuan tahun yang lalu. (Maswinara. 1998).
\end{abstract}

Kata Kunci:, Sains dan Teknologi 


\section{Pendahuluan}

Pendidikan adalah usaha sadar dan terencana untuk mewujudkan suasana belajar dan proses pembelajaran agar peserta didik secara aktif mengembangkan potensi dirinya untuk memiliki kekuatan spiritual keagamaan, pengendalian diri, kepribadian, kecerdasan, akhlak mulia, serta keterampilan yang diperlukan dirinya, masyarakat, bangsa dan negara. (UU RI. No. 20. 2003: 6).

Sebagai usaha sadar dan terencana maka seorang pendidik sudah seharusnya memahami landasan pendidikan. Salah satu landasan pendidikan adalah psikologi. Psikologi berasal dari kata psyche yang berarti jiwa, dan logos yang berarti ilmu. Jadi secara harfiah psikologi berarti ilmu jiwa. (Sarwono, 1992: 16). Dengan pemahaman ilmu kejiwaan maka akan dilahirkan sistem pendidikan yang "berjiwa". Artinya, setiap pendidik menyadari "benang merah" antar dan inter disiplin ilmu yang diajarkan, sehingga nantinya berkembang suatu model pembelajaran yang holistik. Suatu contoh model pembelajaran yang bersifat holistik adalah model pembelajaran agama berwawasan sains teknologi, atau model pembelajaran sains-teknologi berwawasan spiritual(agama). Hal ini dimaksudkan dalam upaya merealisasikan tujuan pendidikan nasional sebagaimana disebutkan dalam UndangUndang Sisdiknas No, 20 tahun 2003, yaitu :

"Berkembangnya potensi peserta didik agar menjadi manusia yang beriman dan bertakwa kepada Tuhan Yang Maha Esa, berakhlak mulia, sehat, berilmu, cakap, kreatif, mandiri dan menjadi warga negara yang demokratis dan bertanggung jawab”. (UU RI No. 20.2003: 11).

Sudahkah tujuan pendidikan nasional ini tercapai ? Beberapa fenomena menunjukkan bahwa belakangan ini anak-anak kita, secara pukul rata tumbuh dalam kesepian dan depresi, lebih mudah marah dan lebih sulit diatur, demikian disebutkan oleh Daniel Goleman dalam buku Working with Emotional Inteligence. (Daniel Goleman, 2001:17). Kasus yang ada di sekitar kita juga menunjukkan bukti bahwa pernyataan Goleman memang mendasar. Salah satu kasus ,"Seorang pelajar nekat bunuh diri”, sementara orang tuanya adalah Sarjana Pendidikan, membuktikan bahwa pendekatan pendidikan sudah 
seharusnya menyentuh paradigma perubahan kejiwaan anak. (Bali Post, 14 September 2007 ) .

\section{Pembahasan}

\section{A. Sains-Teknologi}

Sains-Teknologi", didasarkan pada persepsi mendasar dari perkataan Enstein sebagai bapak sains yang mengatakan "Sains tanpa agama buta, agama tanpa sains lumpuh" (T.D. Singh, Ph.D. 2004). Artinya ; jika para ilmuwan (saintis) tanpa memahami agama maka hasil ilmunya akan dapat menghancurkan diri dan lingkungannya, demikian pula jika rohaniawan (agamais) tanpa pemahaman sains akan menjadikannya egois dan ortodok. Intinya, bukan pada pendekatan bagaimana agama dan sains memulai sebuah Pencarian/

kajian, akan tetapi terletak pada hasil akhir bagaimana kebenaran memunculkan diri menjadi sebuah fakta sains maupun agama. Akhir dari proses pencarian sains adalah kebenaran duniawi dan akhir dari proses pencarian agama adalah kebenaran rohani. Menurut Agama Hindu kebenaran duniawi disebut sebagai hukum Rta (hukum alam) dan kebenaran spiritual disebut hukum Dharma. Kedua hukum ini merupakan satu kesatuan yang disebut sebagai rtam dharmam satyam, hukum alam dan hukum dharma adalah kebenaran.

Perkembangan sains dan teknologi dewasa ini telah menuju pada suatu pendekatan akan peranan sains dalam menjelaskan fenomena spiritual. Toudam Damodara Singh Ph.D, seorang saintis dan juga rohaniawan menyatakan dalam bukunya berjudul The Scientific Basic of Krishna Consciousneess, menyebutkan bahwa ,"Hendaknya sains dijadikan sarana untuk menjelaskan keberadaan Tuhan (Krisna) dan bukannya menjadi semakin jauh dengan prinsip kesadaran mutlak". (T.D. Singh. 2006). Kenyataannya, dalam beberapa bidang pengetahuan, ilmu pengetahuan modern telah menemukan fakta-fakta yang sebelumnya sudah ada dalam literatur Veda ribuan tahun yang lalu. (Maswinara. 1998). Itulah sebabnya Svami Vivekananda menyatakan bahwa, "Penemuan dan penciptaan ilmu pengetahuan modern menyuarakan gema yang kecil dari keagungan raungan singa Vedanta. Demikian pula Dr. Kenneth Walker yang menyanjung kebijaksanaan Veda dan menyatakan : 
"Vedanta merupakan suatu usaha untuk meringkas seluruh pengetahuan manusia dan membuat manfaat seluruh pengalaman manusia. Pada satu saat ia adalah agama, saat lainnya filsafat dan saat lainnya lagi ilmu pengetahuan"(Kenneth Walker dalam Maswinara. 1998)

Dengan demikian, Vedanta memberikan bukti konkret bahwa spiritual dan ilmu pengetahuan terlepas dari pertentangannya merupakan tambahan dan sumbangan timbal balik dalam pencapaian tujuan bersama meningkatkan kehidupan manusia. Sebagai alat untuk mencari kebenaran sains dan agama semestinya menuju kebenaran yang sama dengan metodologi dan keterbatasan masing-masing. (Suja. 2006).

Dewasa ini ilmu pengetahuan mengakui bahwa pengetahuannya dibatasi oleh batas persepsi indra dan pengalaman, sedangkan spiritual, setelah mengambil pengetahuan materi yang tepat memperluas pandangannya jauh kedepan. Namun, kedua bidang pengetahuan ini saling berhubungan sehingga sama-sama penting bagi kesejahteraan umat manusia. Bila ilmu pengetahuan berhubungan dengan 'peralatan' hidup, spiritual berhubungan dengan penyangga peralatan. Bila yang pertama membantu untuk memecahkan teka-teki materi yang belakangan membantu untuk memecahkan misteri kehidupan, penciptaan dan Si Pencipta.(Maswinara. 1998). Pada akhirnya, sains tidak lagi diawali dengan "ragu" akan tetapi memulai dengan suatu keyakinan. Profesor Townes menyampaikanperanankeyakinandalamsainsdan agama sebagaimanadikutip T.D. Singh dalambukuberjudulSeven Nobellaureates on Science and Spirituality, mengemukakansebagaiberikut :

"Sains sendiri memerlukan keyakinan. Kita tidak mengetahui apakah logika kita benar. Saya tidak mengetahui Anda disana. Anda tidak mengetahui saya disini. Lihatlah, kita mungkin hanya bisa membayangkan semua ini. Saya mempunyai sebuah keyakinan tentang seperti apa dunia ini, dan demikian juga saya percaya Anda juga sama. Saya tidak dapat membuktikannya dari sudut pandang fundamental manapun....Namun saya harus menerima ruang lingkup tertentu dimana saya harus bekerja. Pemikiran bahwa agama adalah keyakinan; sains adalah pengetahuan saya kira sangat keliru. Pemikiran ini melupakan dasar sejati dari sains, yaitu keyakinan. Kita para ilmuwan percaya terhadap eksistensi dari dunia eksternal serta keabsahan dari logika kita. Kita merasa nyaman-nyaman saja dengan hal ini. 
Namun demikian, ini semua adalah peranan-peranan keyakinan. Kita tidakdapatmembuktikannya"(T.D. Singh. 2004)

Titik temu sains dan agama bukan saja pada realisasi kebenaran terakhir dari proses pencarian yang panjang, akan tetapi berawal dari bagaimana pencarian itu dilakukan. Upaya untuk menyingkap kebenaran ilmiah dikenal dengan nama metode ilmiah, yang dalam ajaran Hindu dikenal sebagai Tri Premana, yaitu : agama (sastra) premana (pengetahuan berdasarkan kesaksian orang lain), anumana premana (penalaran logika), dan pratyaksa premana (pengamatan langsung). Kerangka berpikir dalam metode ilmiah tersebut yang selama ini diklaim oleh sains telah digunakan ribuan tahun yang lalu dalam Vedanta. Kerangka berpikir tersebut merupakan rangkaian proses logiko-hipotetikoverifikasi, yang pada dasarnya terdiri dari tahap-tahap; perumusan masalah, penyususan kerangka berpikir (sastra premana), perumusan hipotesis (anumana premana), dan pengujian hipotesis (pratyaksa premana) untuk menarik suatu simpulan. (Suja. 2006).

Penjelasan tentang analogi sains dalam Agama Hindu dapat ditemukan dalam uraian Kitab Suci Veda diantaranya dalam Upanisad. Upanisad merupakan kumpulan kitab yang disebut Veda Samhita, yang artinya kitab-kitab yang memuat penjelasan Veda. Upanisad dikenal pula dengan istilah Vedanta, yang berarti kesimpulan akhir dari Veda. (Titib. 1994.). Dalam menjelaskan Veda kitab-kitab Upanisad telah menggunakan sains untuk menjelaskan kebenaran-kebenaran rohani.

Chandogya Upanisad dalam menjelaskan keberadaan Brahman (Tuhan) yang berada dalam diri setiap makhluk menggunakan analogi sebagaimana garam yang larut dalam air, ia tidak nampak namun bisa dirasakan asin. Penjelasan ini disampaikan dalam bentuk dialog antara seorang ayah dengan anaknya. Dialog initerdapatpadaprapathakake 6, chanda 13, yang menyebutkan :

1. Lavanametadudake 'vadhaya, atha ma pratarupasidathaiti :sa ha tathacakara, tam hovacayaddosalavanamudake 'vadhah, anga tad ahareti, tad havamrsyanavivedayathavilinam, evam.

2. Anganasyantadacametikathamiti; lavanamiti; madyatacamati, kathamiti; lavanamiti; antadacameti, kathamiti; lavanamiti; abhiprasyaitadathamopasidathaiti; 
taddhatathacakara, tacchasvatsamvartate, tam hovacaatravavakila sat, saumya, nanibhalayase, atraivakila.

Artinya :

1. Masukanlah garam ini dalam air, dan datang padaku besok pagi”. Ia mengerjakan seperti diperintahkan. Ayahnya berkata kepadanya : "Ambilkan aku garam yang engkau masukkan dalam air semalam" anak itu mencari, tidak menemukannya, karena tentunya, garam itu larut.

2. Ayahnya berkata ,"Rasakan airnya di bagian atas. Bagaimana ?" Anaknya berkata ,"Asin". "Rasakan air di bagian bawah, bagaimana ?". Anaknya berkata ,"Asin”. "Masukkanlah garam kembali ke dalam segelas air dan nanti datanglah kepadaku!” Anak itu mengerjakan seperti perintah ayahnya. Hasilnya selalu sama. Kemudian ayahnya berkata ,’Disini juga, dalam badan ini, tentu engkau tidak melihat yang Maha Tinggi (Sat), sayangku, tetapi Ia pasti ada"(Sadia. 1982. h. 140).

Svetasvatara Upanisad dalam Prapathaka I Chanda 16 juga menyebutkan analogi sains digunakan untuk menjelaskan tentang keberadaan Tuhan.

\section{Tilesu tailam dadhiniva sarpir apas}

srotassuaranisu cagnih

evam atmani grhyate'sau satyenaninam

tapasa yo'nupasyati

Artinya :

Seperti minyak yang dapat diperoleh dari biji sesam dengan jalan meremasnya, mentega dari air susu dengan jalan mengaduknya, air dari dasar sungai yang kering dengan jalan menggalinya, api dari kayu dengan jalan menggosok-gosoknya, demikian juga Diri Yang Maha Agung itu dapat dihayati keberadaan-Nya bila seseorang mencarinya dengan latihan rohani (Titib. 1994. h. 36) 
Sama seperti ungkapan sloka Svetasvatara Upanisad, kitab Arjuna Wiwaha juga mengungkapkan analogi sains dalam menjelaskan metode pencarian personalitas tertinggi (Tuhan) dalam bentuk kekawin, seperti berikut ini :

1. Ong sembah ning anatha tinghalana de triloka sarana, wahyadhyatmika sembah i nghulun i jongta tan hana waneh, sang lwir agni sakeng tahen, kadi minyak sakeng dadhi kita, sang saksat metu yan hana wwang amuter tutur pinahayu.

2. Wyapiwayapaka sari ning parama tatwa durlabha kita, icchantang hana tan hana ganal alit lawan hala hayu, utpatti sthiti lina ning dadi kita ta karana nika, sang sangkan para ning sarat sakala niskalatmaka kita.

3. Sasi wimba haneng ghata mesi banyu, ndan asing suci nirmala mesi wulan, iwa mangkana rakwa kiteng kadadin, ring angambeki yoga kiteng sakala.

4. Katemunta mareka si tan katemu, kahidepta mareka si tan kahidep, kawenangta mareka si tan kawenang, paramarthasiwatwa nirawarana.

Artinya :

1. AumHyangSiwa, sembahhamba yang nistasaksikanlaholeh-MU wahaipenguasatigadunia. Dalamwujudnyatadanabstraksembahsujudhamba-MU kehadapanduli kaki-MU tidakada lain. Engkau bagaikan api yang keluardari kayu dan ibarat minyak yang keluar dari santan. Kepada orang yang menekuniajaransucilahEngkaumenampakkandiri.

2. Meresappadasemuamakhlukhidupdanmerupakaninti sari ajaranutama, sungguhsukarbagiseseoranguntukmenemukanengkau. berkattakdir-MU, menciptakan yang tiada, yang besardankecil, yang baikmaupunburuk. Kelahiran, kehidupanmaupunkematianseseorang, Engkaulahsebagaipenyebabnya. Engkaumerupakanawaldanakhirduniaini, Engkauberwujudnyatasertaabsrak.

3. Bagaikan bayangan bulan di dalam tempayan yang berisi air. Hanya setiap tempat yang suci tanpa noda terlihat bayangan bulan. Seakan-akan demikianlah Engkau terhadap semua manusia. Kepada orang yang sedang melaksanakan yogalah Engkau menampakkan diri.

4. Berhasil Engkau ditemukan yang belum pernah ditemukan. Diketahui Engkau yang belum pernah diketahui. Tercapailah Engkau yang belum pernah dicapai. Kebenaran Siwa tertinggi tak tersulubung (Warna I Wayan. 1988). 
Berdasarkan kutipan-kutipan di atas, dapat kita perhatikan bahwa analogi sains telah digunakan dalam peradaban Veda dalam kurun waktu yang sangat lama. Dalam pencarian kebenaran mutlak yaitu Brahman, Veda menganalogikan seperti menemukan api dalam kayu atau menemukan minyak dalam santan. Untuk memunculkan api dalam kayu seseorang harus menggosokkan kayu sampai muncul api. Analogi yang dimaksudkan disini adalah, cara yang ditempuh untuk memunculkan api dalam kayu merupakan cara kerja sains atau fakta duniawi, akan tetapi keberadaan api di dalam kayu adalah misteri rohani. Demikian pula halnya dengan keberadaan minyak dalam santan. Proses isolasi minyak merupakan kerja ilmiah dan keberadaan minyak dalam kelapa adalah misteri rohani.

\section{Beberapa Contoh Model Pembelajaran Berwawasan Spiritual-Sains-}

Teknologi

Model dapat diartikan sebagai ; contoh, pola, acuan, ragam, dan sebagainya. (Poerwadarminta.1999: 653). Sementara kata pembelajaran diartikan sebagai proses belajar sehingga pembelajar memperoleh hasil belajar. (Rasta.2007:3) Untuk menghindari miskonsepsi, maka model pembelajaran yang dimaksudkan adalah suatu proses belajar yang direncanakan guru dalam upaya meningkatkan kualitas pembelajaran.

Turya, dalam model pembelajaran Agama Hindu berwawasan sains, yaitu penerapan konsep struktur atom dalam menjelaskan filosofis Tat twam asi menjelaskan bahwa :

"Ilmu pengetahuan telah membuktikan bahwa seluruh materi di dunia ini tersusun atas atomatom. Setiap atom tersusun atas tiga partikel utama yaitu proton, elektron dan netron. Kemanapun kita menunjuk, maka hakekatnya adalah partikel atom yang sama. Tak pernah ahli sains maupun rohaniawan menyatakan bahwa hakekat partikel atom dari setiap materi atau zat adalah berbeda, akan tetapi mereka menemukan persamaan dalam perbedaan. Hal ini membuktikan bahwa konsepsi tat twam asi, adalah kebenaran mutlak yang tidak terbantah (Turya.2007: 9)

Tahapan-tahapan yang mesti dilakukan dalam merancang,melaksanakan dan mengevaluasi model pembelajaran Agama Hindu berwawasan Sains, yang dilakukan oleh 
Turya adalah mengikuti teknik classroom action research (CAR). Classroom action researchadalahaction research yang dilaksanakanoleh guru di dalamkelas. (Supriyadi.2007: 1). Karena model pembelajaran ini menggunakan teknik $C A R$, maka rangkaian atau siklus planning-acting-observing-reflecting, mesti dan harus diikuti. Proses acting dapat melibatkan berbagai metode pembelajaran. Dengan kata lain tahapan acting merupakan ramuan strategi pembelajaran yang diterapkan sehingga pembelajaran menjadi menyenangkan.

Contoh lain model pembelajaran Agama Hindu berwawasan Sains adalah suatu model pembelajaran yang dirancang melalui teknik lesson study, yang mana guru mengungkapkan kendala pembelajaran seperti sulitnya siswa memahami landasan mengapa yadnya atau ritual harus dilaksanakan sebagai perwujudan bhakti. Konsepsi sains yang digunakan dalam model ini adalah konsep fotosintesis. Lengkapnya model pembelajaran ini dapat dibaca dalam laporan penelitian berjudul, "Implementasi Lesson Study dalam Pembelajaran untuk Meningkatkan Pemahaman Siswa Tentang Filosofis Yadnya Menggunakan Konsep Fotosintesis ". (Rasta.2007).

Dalam contoh model yang ke dua ini, pola pembelajarannya menggunakan teknik Lesson study, yaitu suatu teknik pembelajaran dengan pembinaan profesi pendidik melalui pengkajian pembelajaran secara kolaraboratif dan berkelanjutan berlandaskan prinsipprinsip kolegalitas dan mutual learning untuk membangun komunitas belajar. (Sumar Hendayana, dkk. 2007:10). Dalam model pembelajaran Agama Hindu berwawasan sains yang menerapkan teknik lesson study maka pembelajaran dilaksanakan dalam siklus plando-see. Dengan kata lain lesson study merupakan suatu cara peningkatan mutu pendidikan melalui penelitian (studi) pembelajaran (lesson) yang tak pernah berakhir (continous improvement).

Pada tahap plan, kolega (guru, dosen, orang tua, pemerhati pendidikan, dll) berdiskusi menganalisis permasalah pembelajaran yang dialami guru (dalam kaitan ini adalah "siswa mengalami kesulitan dalam memahami filosofis yadnya sebagai persembahan atau ritual". 
Setelah menganalisis permasalahan, selanjutnya secara bersama guru dan kolega mendeskripsikan dan menyusun cara, metode pembelajaran yang akan dilakukan sehingga dihasilkan suatu master plan lesson study, pada tahap plan inilah disepakati model pembelajaran yang digunakan, pada contoh ini disepakati menggunankan model pembelajaran berwawasan sains khususnya penerapan konsep fotosintesis untuk menjelaskan filosofis yadnya. Dipilihnya konsep fotosintesis didasarkan pada beberapa argumen antara lain :

1. Fotosintesis adalah suatu proses biologis tumbuhan hijau dalam menyiapkan makanan bagi keseluruhan sel tumbuhan sehingga tumbuhan dapat tumbuh berkembang dan menghasilkan.

2. Dalam proses fotosintesis ada tiga kekuatan yang memberi andil (saham) sehingga proses tersebut dapat berlangsung. Tiga kekuatan ini adalah sinar (unsur cahaya /deva), udara, air, mineral (unsur material /bhuta), dan tenaga pemelihara (unsur manusia).

3. Dari proses awal hingga akhir, tiga kekuatan ini, deva, bhuta, manusia, memberi saham pada proses fotosintesis sehingga tumbuhan dapat tumbuh dan berkembang dengan baik. Sehingga dengan demikian secara wajar dan alami setelah tumbuhan beproduksi tiga kekuatan ini berhak atas saham yang mereka sumbangkan. "Pembagian hasil" atas kerjasama inilah menyebabkan konsep yadnya diberlakukan. Manusia sebagai pemegang otonom, akan membagikan saham kepada deva yang disebut sebagai deva yadnya, dan memberian saham kepada alam material dikenal sebagai bhuta yadnya. Selanjutnya karena manusia dalam bertindak mendapat pengetahuan dari guru, maka guru berhak menerima persembahan, dan peristiwa ini dikenal dengan Rsi dan Pitra Yadnya.

Setelah disusun plan model pembelajaran berwawasan sains (dalam hal ini penjelasan filosofis yadnya dengan konsep fotosintesis), selanjutnya,

pada tahap do, guru yang membidangi melaksanakan pembelajaraan (action lesson) yang diamati oleh beberapa pengamat para kolega (pengawas, komite, serta guru lain). Sebelum melaksanakan action pembelajaran diawali dengan silent sitting, selanjutnya guru memulai pembelajaran. Setiap sesi pembelajaran diselingi diskusi sehingga pembelajar dapat saling tukar pengetahuan. 
Pada tahap $d o$, diperlukan kejelian para observer untuk merekam proses pembelajaran dan tingkah laku siswa. Para observer diharapkan tidak memberikan respon/komentator pada saat proses do lesson study berlangsung. Hal ini dimaksudkan agar guru tidak merasa di intervensi dan siswa juga tidak terintimidasi, sehingga pembelajaran benar-benar berlangsung secara alamiah.

Tahap ke-tiga dari lesson study adalah see (merefleksikan), pada tahap ini dipimpin Kepala Sekolah atau Wakil Kepala Sekolah bidang akademik, guru menyampaikan pengalaman melaksanakan action, kendala proses pembelajaran dalam upaya mengimplementasikan plan yang telah dibuat. Selanjutnya melalui diskusi terpimpin para observer memberi masukan dan saran berdasarkan hasil observasinya selama action lesson dilakukan.

Demikianlah dua contoh model pembelajaran Agama Hindu berwawasan sains yang dapat kami sajikan dalam uraian singkat ini. Pada model pertama, (Penerapan Struktur Atom dalam Menjelaskan Filosofis Tat Twam Asi), pembelajaran dilaksanakan dengan teknik CAR (Classroom Action Research), sedangkan pada model ke dua, (Meningkatkan Pemahaman Siswa tentang Filosofis Yadnya Menggunakan Konsep Fotosintesis), pembelajaran dilaksanakan dengan teknik Lesson Study. Hasilpembelajarandarikedua model inimenunjukkanbahwa :

1. Penerapan konsep struktur atom dalam menjelaskan filosofis tat twam asi secara signifikan dapat meningkatkan pemahaman siswa, serta siswa memberi respon positip terhadap model pembelajaran yang dilaksanakan. (Turya.2007:24)

2. Pemahaman siswa tentang filosofis yadnya mengalami peningkatan secara signifikan setelah penjelasan dilakukan secara ilmiah menggunakan konsep sains (dalam kasus ini konsep fotosintesis) (Rasta.2007:30).

Berdasarkanhasilakhirpembelajarandarikedua model pembelajaran, Agama Hindu berwawasansains di atas, yang menunjukkanbahwasecarasignifikanadapeningkatankualitaspembelajaran, makadapatdikatakanbahwaimplementasi model pembelajaran Agama Hindu berwawasansainsdapatmeningkatkankualitaspembelajaran yang bermuarapadapeningkatanmutupendidikan. 


\section{Penutup}

Berdasarkan uraian di atas, dapat disimpulkan bahwa :

1. Konsep Agama Hindu berwawasan sains, dua diantaranya adalah penerapan konsep struktur atom dalam menjelaskan filosofis tat twam asi, dan meningkatkan pemahaman tentang filosofis yadnya menggunakankonsep fotosintesis.

\section{DAFTAR PUSTAKA}

Art-ong Jumsai Na Ayudhya, B.A, MA, D.I.C, Ph.D. Integration of Human Values in Sciences and Mathematics. Bangkok : Internal Institute of SathyaSaiPubliser.

AndriasHarefa. 2004. MenjadiManusiaPembelajar. Jakarta : Harian Kompas.

Daniel Goleman. 2001. Working with Enotional Intelegence, Kecerdasan Emosi untuk Mencapai Puncak Prestasi. Alih bahsa Alex Tri Kantjono Widodo. Jakarta : PT. Gramedia.

Maswinara Wayan. 1998. Ilmu Pengetahuan dan Spiritual Berdasarkan Veda. Surabaya : Paramita Sumar Hendayana, dkk. 2007. Leson Study Pengalaman Lapangan. Bandung : IMSTEP-JICA. Sadia. 1982. Chandogya Upanisad. Jakarta : Maya Sari. Paramita.

Sri Satya Sai Trust. 1998. Ilmu Pengetahuan dan Spiritual Berdasarkan Weda. Surabaya :

Sri Srimad A.C. Bhaktivedanta Swami Prabhupada. 2004. Kehidupan berasal dari Kehidupan. Jakarta : Hunuman Sakti.

Sri Swami Siwananda. 1994. Intisari Ajaran Hindu. Surabaya : Paramita.

Suja Wayan. 2000. Titik Temu IPTEK dan Agama Hindu. Denpasar : Manik Geni.

2006. Sains Veda Sinergisme Logika Barat dan Kebijakan Timur. Denpasar :

Raditya.

Supriyadi. 2007. Classroom Action ReaeRCH. Bogor: Makalah Workshop.

Tika. 2004. Mewujudkan Pendidikan Masa Depan yang Bermoral dan Berkualitas di Era

Otonomi Daerah. Makalah Seminar.

T.D. Singh Ph.D. 2004. Seven Nobellaureates on Science and Spirituality. Kalkuta : Bhaktivedanta Institute.

T.D. Singh Ph.D. 2005. Vedanta dan Sains Kehidupan dan Asal Mula Jagat Raya.. Jakarta : Hanuman Sakti.

T.D. Singh Ph.D. 2006. The Scientific Basis of Krisnha Consciousness. Kalkuta : .

Titib I Made. 1994. Untaian Ratna Sari Upanisad. Denpasar : Yayasan Dharma Narada.

1998. Veda Sabda Suci Pedoman Praktis Kehidupan. Surabaya : Paramita. 